УДК 316.74

$10.17213 / 2075-2067-2020-6-39-44$

\title{
ТЕОРЕТИКО-МЕТОДОЛОГИЧЕСКИЕ ОСНОВАНИЯ ИЗУЧЕНИЯ ЭТНОКУЛЬТУРЫ МЕДИЦИНСКОГО ТУРИЗМА
}

\author{
(C) 2020 г. B. A. Бахтин
}

Донской государственный технический университет, г. Ростов-на-Дону, Россия

Целью исследования является установление теоретико-методологических оснований, необходимых для проведения исследований в сфере этнокультуры медицинского туризма.

Методологическая база исследования в общетеоретическом плане основывается на социологических теориях этноса в сочиокультурном аспекте, имеющих потенщиал для изучения этнокультуры медицинского туризма.

Результаты исследования. Важнейшим аспектом проведенного анализа, позволяющим прийти к теоретически и эмпирически значимым результатам, является установление социиокультурного смысла признаков этноса с позищий их соотношения со здравоохранительными и конкретно медицинскими проблемами. Этничность глубоко укоренена в культуру. Это приводит к тому, что различные этносы обладают разными формами реагирования в определенных видах деятельности. Эти формы зависят от иееностей, стереотипов, установок, традииий, паттернов и т.д. В полном объеме подобный вывод касается и такой сферы, как медицина. Поведение сочиальных акторов в сфере медицины обусловлено сочиокультурныли факторами, которые в значительной степени опосредуются категорией этничности, поэтому мы убеждены, что процессы, протекающие в сфере медицинского туризма, зависят от сложившегося комплекса, где в равной мере смешиваются соииокультурные основания, этнические и медицинские. Причем последние в значительной степени зависят от ресурсов, которые имеются в каждом конкретном социуме. Эти ресурсы определяют траектории медицинского туризма, корректируемые этничностью в рамках заданных социокультурных границ.

Перспективы дальнейших исследований авторы усматривают в применении сконструированных теоретико-методологических оснований к изучению потенциала медицинского туризма в разных этнических практиках.

Ключевые слова: медицинский туризм; этнос; этнокультура; теоретико-методологические основания; лингвистическое пространство; общность культуры; этнические символьи.

\section{THEORETICAL AND METHODOLOGICAL FOUNDATIONS STUDIES OF ETHNOCULTURE OF MEDICAL TOURISM}

\author{
(C) 2020 V. A. Bakhtin
}

\section{Don State Technical University, Rostov-on-Don, Russia}

The aim of the study is to establish the theoretical and methodological foundations necessary for conducting research in the field of ethno-culture of medical tourism. 
The methodological base of the research in general theoretical terms is based on the sociological theories of ethnos in the socio-cultural aspect, which have the potential to study the ethno-culture of medical tourism.

Research result. The most important aspect of the analysis, which allows us to come to theoretically and empirically significant results, is the establishment of the socio-cultural meaning of the signs of an ethnic group in terms of their relationship to health and, specifically, medical problems. Ethnicity is deeply rooted in culture. This leads to the fact that different ethnic groups have different forms of response in certain activities. These forms depend on values, stereotypes, attitudes, traditions, patterns, etc. In full, this conclusion applies to such areas as medicine. The behavior of social actors in the field of medicine is determined by socio-cultural factors, which are largely mediated by the category of ethnicity. Therefore, we are convinced that the processes taking place in the field of medical tourism depend on the existing complex, where socio-cultural, ethnic and medical grounds are equally mixed. Moreover, the latter largely depend on the resources that are available in each particular society. These resources determine the trajectories of medical tourism, adjusted by ethnicity within the given socio-cultural boundaries.

Prospects of the study. The authors see prospects for further research in the application of the constructed theoretical and methodological foundations to the study of the potential of medical tourism in different ethnic practices.

Key words: medical tourism; ethnos; ethnoculture; theoretical and methodological foundations; linguistic space; community of culture; ethnic symbols.

Введение. Вопрос о привлечении иностранных граждан в лечебные учреждения России продолжает оставаться очень острым. Здесь возможны новые подходы, которые пока не применяются. Имеется в виду, что медицина - это часть культуры, и она не может не испытывать на себе влияние традиций, национального менталитета. Приезжающие из-за рубежа пациенты могут испытывать определенные трудности в культурной адаптации (лингвистические проблемы, незнание местных обычаев, настороженность при употреблении блюд национальной кухни и т.п.). Следовательно, необходимы меры по этнокультурной адаптации медицинских туристов. Это будет способствовать формированию положительных установок на лечение в России.

Bce сказанное подтверждает необходимость научного изучения возможности использования этнокультурных факторов в медицинском туризме. В категориальном поле медицинских наук это сделать нельзя из-за отсутствия соответствующей проблематики и терминологического аппарата. В контексте медицинских наук можно только описать методы лечения болезней в тех или иных кли- никах. Но социология культуры предоставляет возможность изучить проблему и как медицинскую, и как культурологическую, и как этнологическую, поскольку обладает методологией научного синтеза всех перечисленных областей знания.

Основная часть. Самоутверждение этноса путем сохранения единой, отличной от других, культуры, культурные коды этнической самоидентификации реализуются в условиях поливариантности этнических миксаций. Контрадикция мультикультурализма и инкультуральности придает указанному процессу новый смысл, который нельзя оценивать однозначно. Существуют положительные эффекты нового «великого переселения народов», когда взаимопроникновение культур способствует их расцвету и взаимообогащению, но существуют и риски утраты этнической культуры, которые порождают стремление защитить ее социально агрессивными способами. Особенно мучительным становится противоречие между этими двумя тенденциями, когда предметом спора выступают высшие ценности - жизнь и здоровье, поэтому феномен медицинского 
туризма в данных условиях требует глубокого анализа и выработки единой точки зрения. Не препятствует ли усилиям по сохранению и восстановлению здоровья стремление к защите этнокультуры конкретными странами и народами? Не является ли коммерческая составляющая медицинского туризма скрытой угрозой для сохранения уникальной этнической культуры? Не ущемляются ли этнические интересы и свобода развития этнической культуры при ориентации здравоохранения в конкретной стране на все более широкое предоставление медицинских услуг иностранцам? Возможно, ответы на эти и другие подобные вопросы смогут помочь и в решении общей проблемы сохранения этнокультур в современном полиэтничном обществе. Но прежде чем отвечать на них, необходимо определиться с дефинициями основных понятий, поскольку здесь также нет устоявшегося единодушия исследователей. Мы постараемся определить, что понимается в работе под терминами «этнос», «этнокультура», «медицинский туризм», «лечебный туризм».

В своем исследовании мы будем опираться на позицию Ю. В. Бромлея и Л. Н. Гумилева, выражающих единую точку зрения о пяти признаках этноса: территория расселения, обеспечиваемая эндогамией, язык, общность культуры, единство хозяйственной жизни, самоназвание и самосознание $[1,2]$ - с включением выдвинутого Н.Н. Седовой шестого признака этноса — генетической определенности [4]. Очевидно, что каждый этнос как биосоциальное образование именно в своей биологической природе содержит признаки, по которым его представители внешне отличаются друг от друга. А это явный показатель наличия генетических отличий. Сейчас уже достаточно хорошо разработаны этнические портреты этносов, хотя проблем здесь еще много [5]. Важно отметить, что культурный профиль этноса может теоретически включать установку на сохранение своей генетической определенности. Следовательно, социокультурный портрет здоровья будет конструироваться на основе представлений о генетической уникальности, что в свою очередь будет закрепляться в традициях, обычаях, нормах поведения. Их отражение в духовной культуре закономерно. Правда, здесь стоит вопрос об объекте ценностного отношения к здоровью: будет ли это здоровье индивида, общества или этноса? Это важно для понимания принятия/непринятия практик медицинского туризма.

Следует отметить, что лингвистическое пространство медицинского сообщества недифференцировано, поскольку включает единый для всех медицинских работников латинский и греческий языки, да и абсолютное число заболеваний - общее для представителей любых этносов, хотя есть и специфические болезни, которые встречаются у определенных этносов и не бывают у других. В отношении групп болезней с середины 50-х гг. прошлого века накоплен достаточный материал в этногенетике [7].

В медицинской литературе часто отмечается, что связь этничности и заболеваемости - опосредованная, через влияние социальных условий жизни и воспитания, а также через воздействие этнических традиций, прежде всего, в области гигиены. Другими словами, нельзя сказать, что представители конкретного этноса обязательно будут страдать специфическим для данной популяции заболеванием. Все зависит от внешних факторов и личностных особенностей. Например, у малых народов севера, как известно, легко возникает алкогольная зависимость в связи с отсутствием в организме ферментов, расщепляющих алкоголь. Она формируется уже после первого употребления алкоголя, но ее никогда не будет, если человек ни разу не употребит алкоголь. Безусловно, исключением являются наследственные болезни. Таким образом, этническая предрасположенность к определенным заболеваниям - это возможность. Действительностью она становится по социальным причинам. Все сказанное позволяет заключить, что связь между здоровьем и этнической принадлежностью существует и является личностно и социально значимой.

Сообразуясь с этой схемой, можно описать социокультурный смысл признаков этноса с позиций их соотношения со здравоохранительными и конкретно медицинскими проблемами (табл. 1).

Мы согласны с профессором Н.Н. Ceдовой в том, что «вопрос о персонификации конъюнкции этнических и наднациональных ценностей медицины представляется соци- 
ально значимым и требующим выработки единого подхода» [4, с. 23], но не согласны с тем, что таким подходом может стать биоэтика, если будут эксплицированы ее этнические смыслы. Нам представляется, что это слишком узкий подход. Поясним эту мысль.

Современное развитие биомедицинских технологий, безусловно, содержит социальные риски гуманитарного характера. Конвергенция живого и неживого в перспективе открывает большие возможности для лечения самых проблемных заболеваний и совершенствования организма человека. Но одновременно возникает вопрос о том, будет ли этот совершенный человек человеком? Естественно, общество обращается к результатам этической экспертизы новых биотехнологий. Биоэтика востребована, она активно развивается. Однако интерес для общества представляют не только этические, но и эс-

Таблица 1

\section{Социокультурный смысл признаков этноса с позиций их соотношения со здравоохранительными проблемами}

Признак этноса и его актуализация в медицине и здравоохранении
Культурологические проблемы актуализации признака этноса в медицине и здравоохранении

\section{Территория расселения}

Основная переменная в теоретической и практической эпидемиологии.

Одна из переменных в персонализированной медицине.

Право на охрану здоровья некоренных этносов и мигрантов.

Противопоставление коренных и некоренных народов.

Сохранение природных факторов здоровья (связь с экологической этикой).

\section{Единство хозяйственной жизни}

Уровень развития здравоохранения. Уровень оказания медицинской помощи и ее структура.

Уровень научного обеспечения медицины.

Доступность медицинской помощи.
Национальные модели здравоохранения и их комплементарность.

Компаративная биоэтика.

Финансирование здравоохранения.

Этические стимулы для развития национальных медицинских школ

\section{Обциность культуры}

Традиции культуры, определяющие Иерархия моделей врачевания, статус врача. внутреннюю картину болезни.

Отношение к медицине вообще и к врачам как социальной группе.

Народная медицина.

Проблемы стигматизации при социально значимых болезнях.

Пределы применения народной медицины, вопросы самолечения.

\section{Самосознание и самоназвание}

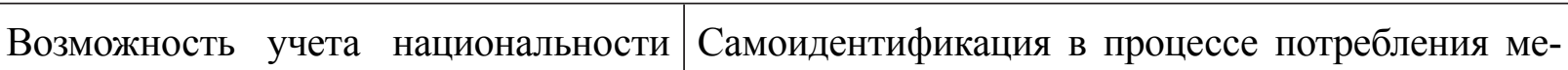
пациента при оказании медицинской дицинских услуг (особенно в случае детей, рожпомощи.

Медицинская статистика.

Медицинский туризм. денных в межнациональных браках).

Этнические предпочтения врачей в процессе оказания медицинской помощи.

\section{Язык}

Диалог с пациентом.

Международные связи в медицинском сообществе.

Ведение медицинской документации.

Практика медицинской лингвистики.

Врачебные ошибки вследствие языковой неадаптированности.

Ситуация врача и/или пациента в иноязычной среде. 
тетические, религиозные, лингвистические ценности, историческая преемственность обычаев и традиций, рефлексия происходящего в художественной литературе и т.п. Другими словами, внедрение новых биотехнологий затрагивает комплекс духовных ценностей, отношение к ним меняется, они сами модифицируются, не говоря уже о том, что в условиях цифровой цивилизации принципиально изменяются способы передачи этих ценностей и закрепления их в мировоззрении нового поколения. Поэтому мы считаем, что конъюнкция этнических ценностей и ценностей здоровья наиболее полно может быть объяснена только в научном поле социологии культуры и духовной жизни. Пока исследований на эту тему явно недостаточно, но уже можно говорить о том, что этнические феномены современной медицины и здравоохранения названы, описаны и получили аксиологическую интерпретацию, правда, пока только на уровне обыденного сознания.

Системообразующим признаком этноса является его культура. Это связано с тем, что она суть аксиологическая экспликация всех остальных признаков. Этнической культуре посвящено много исследований, особенно в последнее время, как в этносоциологии, так и в социологии культуры [6]. Можно сказать, что изучение этнокультуры является кроссдисциплинарным полем для этих дисциплин. Авторы интересуются конкретными проблемами культуры этносов, соотношением этнокультуры и национальной культуры, отдельными элементами этнокультурного облика народов и т.п., но все они едины в понимании того, что такое этнокультура. Здесь мы не нашли разногласий, более того, часто в разных работах даются идентичные определения этнокультуры. Приведем здесь пример такого типичного определения.

«Этнокультура - это совокупность традиционных ценностей, отношений и поведенческих особенностей, воплощенных в материальной, духовной, социальной жизнедеятельности этноса, сложившихся в прошлом, развивающихся в исторической социодинамике и постоянно обогащающих этнической спецификой культуру в различных формах самореализации людей». И далее: «Этнокультура, включая в себя ряд структурных элементов (традиции, ценности, нормы, обычаи, ритуалы, нормы), образует систему, которая выполняет в социуме взаимодействующую функцию. Одним из наиболее значимых и универсальных этнических символов является язык. Именно он формирует национальное самосознание» [3]. Мы выбрали данное определение не только потому, что оно является типичным, но и потому, что содержит указание на связь этнокультуры с другими признаками этноса.

Связь этнокультуры и здоровья достаточно очевидна. Традиции и обычаи отдельных народов в отношении здоровья и болезни различаются, поэтому различаются и образцы поведения, гигиенические и здоровьесберегающие технологии. Хотя в век высокотехнологичной медицины и господства рыночных отношений унификация медицинских практик является закономерностью, можно отметить сохранение переданных предками установок, навыков и символов, связанных со здоровьем и болезнью.

Выводы. В заключение можно сделать следующие выводы.

1. Этнокультура каждого народа включает медицинские обычаи, традиции, знания и во многом определяет мировоззрение самих медицинских работников.

2. Этносоциология до сих пор не уделяла внимания медицинским компонентам, хотя характеристики моделей врачевания у того или иного народа в этносоциологических исследованиях имеются.

3. Отношение к здоровью в контексте этногенеза целесообразно изучать в терминах социологии культуры, поскольку оно включено в культурные стереотипы на индивидуальном уровне.

\section{Литература}

1. Бромлей Ю. В. Очерки теории этноса. 3-е изд., исправленное. - М.: Книжный дом «Либроком», 2009. - 436 с.

2. Гумилев Л.Н. Этнос - состояние или процесс? (Ландшафт и этнос: XI) // Вестник ЛГУ. - 1971. - №12. - Вып. 2. - С. 86-95.

3. Истории происхождения термина: этнос, этнокультура [Электронный ресурс]/ Мультикурс. - Режим доступа: https:// multiurok.ru/blog/istorii-proiskhozhdieniia- 
tiermina-etnos-etnokul-tura.html (Дата обращения: 13.12.2018).

4. Седова Н.Н. Биоэтика этноса или этническая биоэтика? // Биоэтика. — 2013. №2. - С. 3-9.

5. Степанов B. A. Геномы, популяции, болезни: этническая геномика и персонифицированная медицина // Acta naturae. - 2010. T. 2. - №4 (7). - C. 20-27.

6. Тарбастаева И.С. Коллективные права этнических сообществ как условие сохранения этнокультурного разнообразия // Сибирский философский журнал. - 2018. T. 16. - №3. - C. 143-151.

7. Cann R.L., Stoneking M., Wilson A. C. // Nature. - 1987. — Vol. 325. - P. 31-36.

\section{References}

1. Bromlej Ju. V. Ocherki teorii jetnosa [Essays on the theory of ethnos]. 3-e izd., ispravlennoe. - Moscow: Knizhnyj dom «Librokom», 2009. - $436 \mathrm{p}$.

2. Gumilev L.N. Jetnos - sostojanie ili process? (Landshaft i jetnos: HI) [Ethnos state or process? (Landscape and ethnos: XI)] //
Vestnik LGU. — 1971. — №12. - Issue 2. Pp. 86-95.

3. Istorii proishozhdenija termina: jetnos, jetnokul'tura [The history of the origin of the term: ethnos, ethnic culture] [Jelektronnyj resurs]/ Mul'tikurs. - URL: https://multiurok.ru/blog/ istorii-proiskhozhdieniia-tiermina-etnos-etnokultura.html (Date accessed: 13.12.2018).

4. Sedova N.N. Biojetika jetnosa ili jetnicheskaja biojetika? [Bioethics ethnic group or ethnic bioethics?] // Biojetika [Bioethics]. 2013. - №2. - Pp. 3-9.

5. Stepanov V.A. Genomy, populjacii, bolezni: jetnicheskaja genomika i personificirovannaja medicina [Genomes, populations, diseases: ethnic genomics and personalized medicine] // Acta naturae. - 2010. - Vol. 2. — №4 (7). - Pp. 20-27.

6. Tarbastaeva I.S. Kollektivnye prava jetnicheskih soobshhestv kak uslovie sohranenija jetnokul'turnogo raznoobrazija [Collective rights of ethnic communities as a condition of maintaining ethno-cultural diversity] // Sibirskij filosofskij zhurnal [Siberian philosophical journal]. 2018. - Vol. 16. — №3. - Pp. 143-151.

7. Cann R.L., Stoneking M., Wilson A. C. // Nature. - 1987. — Vol. 325. - P. 31-36.

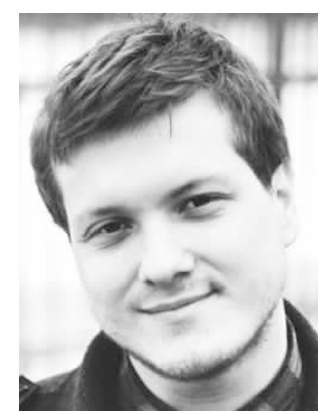

Бахтин Виктор Александрович - преподаватель кафедры «Сервис, туризм и индустрия гостеприимства» Донского государственного технического университета.

Bakhtin Vicktor Alexandrovich - Lecturer of the Department «Service, Tourism and Hospitality industry», Don State Technical University.

344000 , г. Ростов-на-Дону, ул. 24-я Линия, 2/5

2/5 24th Liniya st., 344000, Rostov-on-Don, Russia

E-mail: bakhtinvictor@icloud.com 